\title{
Consensus statement: Supporting Safer Conception and Pregnancy For Men And Women Living with and Affected by HIV
}

\author{
Lynn T. Matthews ${ }^{1} \cdot$ Jolly Beyeza-Kashesya $^{2} \cdot$ Ian Cooke $^{3} \cdot$ Natasha Davies $^{4} \cdot$ \\ Renee Heffron $^{5}$ - Angela Kaida ${ }^{6} \cdot$ John Kinuthia $^{7}$ - Okeoma Mmeje ${ }^{8}$. \\ Augusto E. Semprini ${ }^{9} \cdot$ Shannon Weber $^{10}$
}

Published online: 13 May 2017

(c) The Author(s) 2017. This article is an open access publication

\begin{abstract}
Safer conception interventions reduce HIV incidence while supporting the reproductive goals of people living with or affected by HIV. We developed a consensus statement to address demand, summarize science, identify information gaps, outline research and policy priorities, and advocate for safer conception services. This statement emerged from a process incorporating consultation from meetings, literature, and key stakeholders. Three co-authors developed an outline which was discussed and modified with co-authors, working group members, and
\end{abstract}

Lynn T. Matthews

1tmatthews@mgh.harvard.edu; 1tmatthews@partners.org

Renee Heffron

rheffron@uw.edu

Angela Kaida

angela_kaida@sfu.ca

1 MGH Global Health and Division of Infectious Diseases, 125 Nashua Street, Suite 722, Boston, MA 02114, USA

2 Department of Obstetrics and Gynaecology, Mulago National Referral Hospital, Kampala, Uganda

3 University of Sheffield, Sheffield, UK

4 University of the Witwatersrand, WITS RHI, Johannesburg, South Africa

5 University of Washington, Seattle, USA

6 Faculty of Health Sciences, Simon Fraser University, Burnaby, British Columbia, Canada

7 University of Washington, Kenyatta National Hospital, University of Nairobi, Nairobi, Kenya

8 University of Michigan, Ann Arbor, USA

9 University of Milan, Milan, Italy

10 University of California at San Francisco, Zukerberg San Francisco General Hospital, San Francisco, USA

additional clinical, policy, and community experts in safer conception, HIV, and fertility. Co-authors and working group members developed and approved the final manuscript. Consensus across themes of demand, safer conception strategies, and implementation were identified. There is demand for safer conception services. Access is limited by stigma towards PLWH having children and limits to provider knowledge. Efficacy, effectiveness, safety, and acceptability data support a range of safer conception strategies including ART, PrEP, limiting condomless sex to peak fertility, home insemination, male circumcision, STI treatment, couples-based HIV testing, semen processing, and fertility care. Lack of guidelines and training limit implementation. Key outstanding questions within each theme are identified. Consumer demand, scientific data, and global goals to reduce HIV incidence support safer conception service implementation. We recommend that providers offer services to HIV-affected men and women, and program administrators integrate safer conception care into HIV and reproductive health programs. Answers to outstanding questions will refine services but should not hinder steps to empower people to adopt safer conception strategies to meet reproductive goals.

Key Terminology

Safer conception strategies or programs

PLWH, WLWH, MLWH
Strategies or programs that support people living with HIV and/or their partners to achieve pregnancy with minimal risks of sexual transmission of HIV

Persons or person living with HIV, women or woman living with HIV, men or man living with HIV 
HIV-affected couple

HIV-serodiscordant couple or partnership
A couple or partnership in which at least one member of the partnership is living with HIV

A couple or partnership in which one member of the partnership is living with HIV and the other is HIV-negative

\section{Context and Purpose}

Globally, at least $20-50 \%$ of men and women living with HIV want to have children [1-4]. For many HIV-affected individuals and couples, attempting pregnancy introduces risks of HIV transmission to infants and HIV-uninfected partners. Antiretroviral-driven HIV-prevention strategies reduce risks of HIV transmission through pregnancy attempts and pregnancy. Programs to prevent or eliminate maternal-to-child-transmission (PMTCT/EMTCT) reduce perinatal transmission to less than $2 \%$ for women living with HIV [5]. Antiretroviral therapy (ART) extends the health and survival of people living with HIV (PLWH) to a life expectancy equivalent to that of HIV-negative persons $[6,7]$. Furthermore, HIV prevention programs offer multiple approaches to reduce sexual HIV transmission risk during condomless sex $[8,9]$ : these can be promoted when people affected by HIV desire and attempt pregnancy.

A growing body of evidence suggests opportunities for widespread promotion of safer conception counseling and service delivery. Safer conception interventions reduce HIV incidence while supporting the pregnancy goals of men and women living with or affected by HIV. Safer conception program outputs dovetail with global goals to enhance HIV testing, ART uptake, and HIV-RNA suppression, and thus reduce HIV incidence and eliminate perinatal transmission. However, a limited number of country-level policies and a lack of global guidelines leave providers unprepared to counsel clients. Therefore, grounded in a reproductive rights-based framework, with foundations in scientific data and community values, we developed this consensus statement to: articulate experiences with and address growing demand for safer conception services; summarize the science; identify information gaps; outline research and policy priorities; and advocate for action.

\section{History of Growing Consensus on Safer Conception}

This consensus statement was motivated by discussions over the last decade. Safer conception research, policy, and implementation has been highlighted at international meetings [10-15] [16-18], leading journals have

highlighted research in this field through supplements [19] [20, 21] [22], and several organizations advocate for and provide safer conception care for persons-affected by HIV [23] [24] [25]. The Global Network of People Living with HIV [15] and the International Community of Women Living with HIV [26] endorse safer conception programming and sexual and reproductive health and rights for people living with or affected by HIV. Canada [27, 28], South Africa [29], and the UK [30]) have national guidelines offering comprehensive safer conception guidelines.

\section{Call for Consensus Document}

The call for this global consensus statement to advocate for safer conception implementation emerged from a satellite session at the International AIDS Society 2015 Conference titled "Achieving pregnancy while minimizing HIV transmission risks: Safer conception research, policy, and programming priorities for HIV-affected individuals and couples" [31]. This session convened approximately 180 stakeholders from 25 countries including PLWH, clinicians, researchers, policy makers, community advocates, and donor agencies.

\section{Our process}

This document emerged from a consultative process incorporating input from the above meetings, literature, and discussions with key stakeholders. Three co-authors (LTM, RH, AK) developed a draft outline of the manuscript which was discussed and modified with co-authors and other experts in safer conception, HIV treatment and prevention, fertility, and perinatal transmission.

The updated outline informed a draft of the statement and feedback was sought from co-authors and key stakeholders (consumers, persons living with HIV, research and clinical leaders in safer conception). Feedback was integrated to develop a penultimate draft of the manuscript. All co-authors approved the final draft of the consensus guidelines. Subsequently, the statement was posted online and circulated to key stakeholders including organizations, clinicians, community members, researchers, and advocates in sexual and reproductive health, fertility, and HIV for endorsement (https://www.hiveonline.org/safe rconceptionendorse/).

\section{Consensus}

We summarize the evidence regarding demand for, strategies for, and implementation of safer conception services. Several related topics such as contraception, antiretroviral treatment choices during pregnancy, perinatal 
transmission of HIV, and breastfeeding practices are not explicitly covered in this document. We outline key questions that remain unanswered and suggest steps for the way forward. We articulate the need for action to provide services to minimize pregnancy-related HIV transmission risks while supporting the sexual and reproductive goals of men and women affected by HIV. We urge providers and policy-makers to support safer conception service implementation even as research and advocacy continue.

\section{Demand for Safer Conception Services: Evidence}

For most men and women, an HIV diagnosis does not eliminate hopes or plans to have children, yet few access safer conception care [32-35]. Individual stories articulated by people living with HIV highlight the demand and opportunities for service delivery (See Box 1).

The demand, opportunities, and challenges expressed in these stories echo throughout the literature. Most men and women living with or affected by HIV have limited awareness about HIV prevention options that reduce transmission during condomless sex $[35,36]$. Providers do not initiate conversations about reproductive goals with HIV-affected clients [33, 35, 37-39] and anticipated stigma from providers is a barrier to seeking care [34, 40, 41]. In addition, individuals and couples who want to have children may not explicitly plan for pregnancy, limiting opportunities for pre-conception counseling [35, 42, 43]. HIV counseling and testing can be an entry point to discussions about pregnancy plans and safer conception care but uptake of pre-conception HIV testing is low [44]. Furthermore, this is not a one-time conversation, as reproductive goals evolve over time. For many seeking pregnancy, reproductive services and/or fertility evaluation may be necessary, but ongoing stigma and limited resources constrain access to fertility services for PLWH. Among those who know their serostatus, barriers to disclosure to sexual partners and confusion about serodiscordance limit recognition that conception attempts may be accompanied by HIV exposure [40, 45, 46]. When discussion about safer conception is started, provider guidance about the various methods is desired [47, 48]. Men's voices are nearly absent in conversations about sexual and reproductive health for persons living with or affected by HIV [49]. Furthermore, many men and women make decisions and plans regarding reproductive goals together with families and communities where knowledge of safer conception opportunities is low. See Table 1 for summary consensus points in the area of Demand for Safer Conception Services.

Box 1 Pregnancy experiences of HIV-affected men and women

Jacque is a Kenyan woman in her early $40 \mathrm{~s}$. She was diagnosed with HIV in 2004. 5 years after learning her positive HIV status, she discovered she was pregnant again. Although this was an unplanned pregnancy, it was not unwanted. Her partner at the time was also living with HIV. The reaction of her community as they learned that she was a pregnant woman living with HIV surprised her. They questioned why a woman living with HIV would become pregnant and accused her of wanting to give her unborn child AIDS. Nonetheless, she carried on with the pregnancy, received PMTCT care, and was blessed with a son who is now 7 years old and HIV-negative. However, Jacque's experiences of stigma and discrimination throughout her pregnancy caused her to limit her desire to expand her family further, until recently

She now has a partner who is HIV-negative and he would like to have a child with her. He is concerned about acquiring HIV and the risks to a future baby. He does not know if it is possible to conceive with an HIV-positive partner and anticipates facing judgment from his family, community, and healthcare providers. As an activist and well-informed woman, Jacque knows that safer conception is possible but feels the burden of responsibility to find a willing provider or take it upon herself to educate and inform her HIV care providers to support the fertility desires she and her partner now have

$J_{u a n}{ }^{\mathrm{a}}$ is a North American man living with HIV. When he was diagnosed with HIV in 2008, he worried about whether he would be able to have a family. Juan's provider asked him about whether or not he wanted a child in the future, discussing the options together. When Juan began dating Monica, she came to clinic with him and learned about reducing HIV transmission, including pre-exposure prophylaxis/PrEP. Monica chose to take PrEP and stay on contraception until she finished school. After graduating, she continued PrEP and became pregnant. Monica remains HIV-negative and delivered an HIV-negative baby. Juan remains engaged in care and maintains an undetectable HIV-RNA viral load

Lisa is a young Canadian woman who acquired HIV infection via perinatal transmission. As a young child, she received HIV care including antiretroviral therapy through a local clinic for HIV-infected children, women, and their families. In her $20 \mathrm{~s}$, Lisa fell in love with and married an HIV-negative man. When the couple decided to expand their family, they sought guidance from Lisa's HIV providers, with whom she had developed a trusting relationship. Lisa's care providers supported her pregnancy plans and offered the couple safer conception counseling. Lisa successfully used ART and had an undetectable viral load for at least six months before the couple started having sex without condoms to try to get pregnant. They paid attention to time their condomless sex to days with high fertility. Within a year, Lisa and her husband welcomed a baby girl. Both her husband and baby remain HIV-uninfected. Lisa credits her supported journey to motherhood to her HIV care providers' commitment to integrated, women-centered, and holistic management of HIV, from diagnosis, treatment initiation, and conception, to pregnancy, postpartum, and beyond

Stories articulated by the men and women represented above. Edited by the authors

a Pseudonym 
Table 1 Summary group consensus points based on the available evidence

Demand for safer conception services

Opportunities for HIV prevention in the context of desired pregnancy

Implementation of comprehensive sexual reproductive health services
- There is widespread demand for safer conception services. In the absence of support for informed decisions about safer conception practices, HIV-affected individuals and couples navigate pregnancy decisions without information to support HIV risk reduction opportunities

- Stigma towards PLWH having children limits access to comprehensive reproductive care

- Insufficient knowledge, a lack of normative safer conception guidance, and limited skills regarding safer conception options prevent healthcare providers from initiating conversations about reproductive goals with PLWH and their partners

- Attrition across the HIV care cascade limits the reach and potential of safer conception care. Efforts are required to ensure that HIV prevention services are available to all who require them

- Reproductive goals, risk perceptions, and acceptance of both risks and risk reduction strategies are fluid and thus not readily addressed by one-time counseling

- Safer conception information needs to be shared beyond individual-level clinic counseling to include partners, family members, and communities.

- There is clear scientific evidence regarding efficacy, effectiveness, safety, and client acceptability supporting a range of biomedical and behavioral safer conception strategies

- Antiretroviral treatment (ART) for people living with HIV is indicated for their own health, and also to reduce transmission to partners and (for women) infants at all times, including when pregnancy is intended

- Choices provide options and engage people living with HIV in care. PrEP for HIV-negative partners, limiting condomless sex to peak fertility, home insemination, male circumcision, treatment of sexually transmitted infections, couples-based HIV testing, semen processing and assisted reproductive technologies, and fertility care provide additional HIV prevention options to support individual preferences and the realities of accessible services

- Safer conception service implementation is limited by a lack of guidelines, a lack of service, delivery and population targets, and a lack of training and support for providers to offer these services

- Many providers have ongoing reservations about supporting condomless sex and/or childbearing among PLWH

-When services are made available, demand is high, delivery is feasible, and outcomes are encouraging

- Supporting mutual HIV-serostatus disclosure within the partnership is part of safer conception counseling, but disclosure to a potential pregnancy partner is not a prerequisite for participation

- Legal and ethical issues present challenges to the delivery of safer conception care. Potential clients should be counseled about relevant legal considerations. However, refusal to provide safer conception services violates the reproductive rights of PLWH

\section{Opportunities for HIV Prevention in the Context of Desired Pregnancy: Evidence}

Several strategies allow HIV-affected couples to conceive with minimal transmission risk to the uninfected partner (Table 2). All PLWH, regardless of reproductive plans, are encouraged to initiate ART upon HIV diagnosis to improve their own health, reduce morbidity and mortality, and reduce HIV transmission [50]. When pregnancy is desired, the benefits of ART extend to safer conception. It is ideal for individuals and couples to delay pregnancy attempts until HIV-RNA is suppressed or after at least six months of ART [51, 52].

Because uptake of and adherence to ART is often imperfect or unknown to the partner, individuals may choose additional methods to reduce transmission risk. Pre- exposure prophylaxis (PrEP) is recommended for those at substantial risk of HIV and is an important option for an uninfected partner wishing to conceive with an infected partner whose ART use is suboptimal or unknown [50]. For men or women exposed to HIV and not yet on PrEP, antiretroviral post-exposure prophylaxis (PEP) may reduce HIV acquisition risks and can be offered within $72 \mathrm{~h}$ of exposure and continued for 28 days after exposure [53] [50]. For individuals or couples exposed to HIV as part of conception attempts, PEP may be a bridge to PrEP [42]. When used prior to pregnancy, there are minimal safety or fertility concerns about tenofovir-based PrEP [54, 55]. For uninfected women, safety data about TDF/FTC-based PrEP during pregnancy are based on studies of women living with HIV or hepatitis B exposed to combination ART throughout pregnancy. The data are largely reassuring but 
Table 2 Strategies to reduce periconception risk of HIV transmission for serodiscordant couples

\begin{tabular}{|c|c|c|c|}
\hline Couple & Method & $\begin{array}{l}\text { Estimated risk } \\
\text { reduction }\end{array}$ & $\begin{array}{l}\text { Level of evidence }{ }^{a} \\
\text { [source] }\end{array}$ \\
\hline \multirow{8}{*}{$\begin{array}{l}\text { Either partner infected, pursuing sex without } \\
\text { condoms for pregnancy }+ \text { adjunct risk } \\
\text { reduction strategies (goal: } \downarrow \text { sexual } \\
\text { transmission) }\end{array}$} & Sex without condoms limited to peak fertility & Unknown & $1 \mathrm{~A}$ \\
\hline & & & [96] \\
\hline & ART for the infected partner & $96 \%$ & 1B \\
\hline & & & {$[52,97]$} \\
\hline & $\begin{array}{l}\text { PrEP (oral, daily FTC/TDF or TDF) for the } \\
\text { uninfected partner }\end{array}$ & $63-75 \%$ & $\begin{array}{l}1 \mathrm{~A}^{\mathrm{b}} \\
{[98,99]}\end{array}$ \\
\hline & $\begin{array}{l}\text { Post-exposure prophylaxis (PEP) for the } \\
\text { uninfected partner }\end{array}$ & Unknown & $2 \mathrm{~A}$ \\
\hline & Treatment of STI's & $\leq 40 \%$ & $1 \mathrm{~B}^{\mathrm{c}}$ \\
\hline & & & {$[60,61]$} \\
\hline \multirow[t]{3}{*}{ F + M- (goal: $\downarrow$ female to male transmission) } & Manual self insemination ${ }^{\mathrm{e}}$ & $100 \%$ & $5[58]$ \\
\hline & Medical male circumcision & $66 \%$ & $1 \mathrm{~A}$ \\
\hline & & & {$[59]$} \\
\hline \multirow[t]{2}{*}{ M + F- (goal: $\downarrow$ male to female transmission) } & Sperm washing $^{\mathrm{d}}$ & $\sim 100 \%$ & $2 \mathrm{~A}$ \\
\hline & & & [64] \\
\hline
\end{tabular}

$I U I$ intrauterine insemination, $I V F$ in vitro fertilization, $I C S I$ intracytoplasmic sperm injection, $A R T$ antiretroviral treatment, $P r E P$ pre-exposure prophylaxis, FTC/TDF emtricitabine/tenofovir disoproxil fumarate

a Oxford Centre for Evidence-based Medicine, Levels of Evidence (1A: RCT's with homogeneous support; 1B: individual RCT; 2A: cohort studies with homogeneity; 2C: ecological studies; 5: expert opinion without explicit supporting research) [100]

* Limiting sex without condoms to times of peak fertility reduces exposure, but does not affect HIV-1 transmission risk per coital act

b Effective for heterosexual men in two of two RCTs and for women in two of four RCTs

c Effective in one of six RCTs

d Sperm washing can be followed by introduction to the female partner via cervical cap, IUI, IVF \pm ICSI, depending on available services, client preference, and concerns re. fertility. Additional strategies that support building of healthy families for HIV-affected couples include donor sperm and adoption

e Man ejaculates into a condom or cup and the contents are introduced via condom reversal or needleless syringe at home, or through IUI with a healthcare professional - timed to the woman's peak fertility

inconsistent results suggest possible decreased bone mineral density in newborns, with unknown clinical significance, and one study showed risk of adverse infant outcomes (low birth weight or even stillbirth) among infants exposed to TDF/FTC as part of ART, a finding not replicated in other studies $[55,56]$. This warrants additional data collection among women using PrEP throughout pregnancy. Current guidelines recommend PrEP as a safer conception strategy with discussion of the risks and benefits of continuing PrEP use during pregnancy and breastfeeding [50, 57].

Additional strategies to decrease HIV acquisition by men during pregnancy attempts with a woman living with HIV include vaginal self-insemination, which eliminates the need for condomless sex [58]; and medical male circumcision [59]. Treatment for sexually transmitted infections (STIs) has been shown to further reduce HIV transmission risk [60, 61]. Limiting condomless sex to days with peak fertility [62] maximizes likelihood of achieving pregnancy while limiting HIV exposure.
For HIV-serodiscordant couples where the man is living with HIV, sperm processing or "washing" can isolate sperm (which do not harbor HIV) from seminal plasma and leukocytes [63]. Processed semen can be introduced via intrauterine insemination, in vitro fertilization with or without intracytoplasmic sperm injection, or via a cervical cap. Robust data suggest that this process is safe and effective, with no recorded HIV transmissions to pregnancy partners [64]. This is an important option but should by no means be mandated [65].

Compromised fertility among HIV-affected couples may result in HIV-exposure with minimal chances of pregnancy [66]. Infertility screening may identify couples who would benefit from services to optimize fertility prospects prior to pregnancy attempts [67]. Comprehensive safer conception care also includes offering contraception until couples are ready to attempt pregnancy and/or once they have met their reproductive goals. See Table 1 for summary consensus points in the area of "Opportunities for HIV prevention in the context of desired pregnancy." 


\section{Implementation of Comprehensive Sexual Reproductive Health Services: Evidence}

\section{Normative Guidance}

Few countries have safer conception clinical guidelines. Canada, South Africa, and the UK have guidelines; however, many providers in these locations remain unprepared to counsel clients [35-37, 39, 41, 68, 69]. The WHO recommends ART for all PLWH and PrEP for HIV-exposed persons. Current global EMTCT guidance does not explicitly address safer conception programming.

\section{Systems}

Most safer conception services exist within specialized academic medical centers, private clinics, research projects, or privately funded implementation programs [42, 70-73]. Data show that where services are offered, uptake is high and outcomes are encouraging. These programs provide opportunity to inform future implementation efforts.

\section{Reproductive Rights of People Living with HIV}

A reproductive rights framework recognizes that all couples and individuals, including those living with or affected by HIV, have the basic right to "decide freely and responsibly the number, spacing, and timing of their children and to have access to the information, education, and means to do so" [74]. These rights also include the right to make reproductive decisions "free of discrimination, coercion, and violence". The endorsement of the sexual and reproductive rights of PLWH is essential within safer conception guidelines, policies, and programs as a step towards building trust between providers and HIV-affected clients, given a history of sexual and reproductive rights violations of PLWH [75].

Legal and ethical issues present challenges to safer conception care delivery. Expectations that clients seeking pregnancy disclose HIV status to pregnancy partners must be considered in the context of clients' lives and safety. Supporting safe disclosure is a component of safer conception programming, but not a prerequisite for participation. For many PLWH, particularly women, disclosure is highly challenging and in some cases dangerous-with risks of violence, relationship dissolution, and abandonment [76]. Disclosure challenges are exacerbated in settings where laws criminalize HIV non-disclosure, exposure, and/or transmission to sexual partners [77]. Institutionalized stigma and HIV criminalization are likely to influence willingness of $\mathrm{HIV}$-affected individuals to engage and remain in HIV care [78] and safer conception care.

\section{Providers}

Providers rarely counsel clients about safer conception options [33, 35-39, 41, 68, 79-81]. In addition, many providers retain negative attitudes towards PLWH having children, in part due to experiences caring for children living with HIV, historical recommendations against pregnancy for PLWH, and lingering stigma and discrimination [36, 37, 39, 41, 81, 82]. After decades of focusing on condoms for HIV prevention, providers hesitate to endorse condomless sex [41, 81]. Provider time is limited and in demand. In addition, clients who want safer conception advice often hesitate to ask for it, in part due to the emphasis on condom use and perceptions of provider stigma towards pregnancy among PLWH [34, 40, 41, 82]. HIV-affected men and women may also seek care from traditional healers and other providers who may not have safer conception information [83, 84]. See Table 1 for summary points regarding Implementation of Comprehensive Safer Conception Services.

\section{Key Questions Within the Areas of Demand, Opportunities for Prevention, and Implementation}

We identified key questions within the areas of demand, opportunities for prevention, and implementation. Answers to these questions will improve care and implementation and inform policy, but need not delay service implementation.

\section{Demand}

How to reach at-risk, uninfected men and women who may benefit from safer conception services as well as PLWH not engaged in care or aware of their own or their partner's serostatus is a gap. Normalizing pregnancy desires and pregnancy among people living with and affected by HIV is an outstanding goal to decrease stigma.

\section{Prevention}

The science of HIV prevention offers clear data regarding reduced risk of sexual transmission of HIV, but few methods have been studied in the context of couples or individuals seeking personal or partner pregnancy. Research to understand method use in the context of desired pregnancy is needed. While HIV-RNA suppression would ideally be confirmed prior to conception attempts, this is less feasible in resource-limited settings. 6 months is sufficient for the majority of clients to suppress HIV-RNA 
while taking effective ART. Strategies to test for suppression sooner for those eager to move forward with pregnancy attempts, or for those who feel more comfortable proceeding with proof of HIV-RNA suppression, are needed.

Tenofovir-based PrEP is a relatively new prevention technology and, accordingly, there are ongoing questions. A major challenge is how to best support adherence to PrEP [85]. In addition, there remain outstanding questions regarding the safety of TDF/FTC as prophylactic medication during pregnancy and breastfeeding [86]. Current WHO guidelines recommend PrEP as a safer conception strategy with discussion of the risks and benefits of use during pregnancy [50]—but some regional guidelines caution against use in pregnancy [87, 88]. Data to answer these questions are being collected [42, 72, 89]: how to counsel clients and providers to make informed decisions based on available and evolving data is needed [90].

\section{Implementation}

In early implementation studies, many clients seeking safer conception services have a medical history suggestive of infertility [91, 92]. How to support HIV-affected couples who have compromised fertility is a significant gap. Fertility evaluation after 6 months of timed unprotected sex has been recommended for HIV-negative women older than 35 years [93]. A similar approach has been advocated to minimize the duration of HIV exposure for HIV-affected couples, but there is not consensus about whether a fertility evaluation should be conducted prior to the couple's attempts at achieving pregnancy, or at six or 12 months

Table 3 Resources

\begin{tabular}{lc}
\hline Source & Link \\
\hline Canadian HIV pregnancy planning & http://www.jogc.com/article/S1701- \\
guidelines (2012) & 2163(16)35274-4/pdf \\
& http://www.ncbi.nlm.nih.gov/pubmed/23125998 \\
South African National contraception and & http://www.doh.gov.za/docs/policy/2013/ \\
fertility planning policy and service & contraception_fertility_planning.pdf \\
delivery guidelines (2012) & https://www.health-e.org.za/wp-content/ \\
& uploads/2014/05/ContraceptionPolicy \\
& ServiceDelGuidelines2013.pdf \\
U.S. DHHS Guidelines, Panel on & http://aidsinfo.nih.gov/contentfiles/lvguidelines/ \\
Treatment of HIV-Infected Pregnant & perinatalgl.pdf \\
Women and Prevention of Perinatal & \\
Transmission, & \\
ASRM guidelines on offering assisted & https://www.asrm.org/uploadedFiles/ASRM_ \\
reproductive technologies to HIV- & Content/News_and_Publications/Ethics_ \\
affected individuals and couples & Committee_Reports_and_Statements/ \\
& hivethics.pdf \\
& http://www.reproductivefacts.org/globalassets/ \\
& asrm/asrm-content/newsand-publications/ \\
& ethics-committee-opinions/human_- \\
& immunodeficiency_virus_and_infertility_ \\
treatment-pdfmembers.pdf & http://www.who.int/hiv/pub/guidelines/ \\
WHO, Guidelines for use of & earlyrelease-arv/en/ \\
antiretrovirals (2015) & https://www.hiveonline.org/ \\
HIVE & \\
&
\end{tabular}

GlobalShare Listserv https://www.hiveonline.org/resources/globalshare/

\section{Description}

Comprehensive safer conception guidelines

Safer conception guidelines for South Africa (preceding approval of PrEP in SA)

Safer conception methods for HIVserodiscordant couples are mentioned

Ethics Committee of the American Society for Reproductive Medicine, statement on the safety and ethics of offering assisted reproductive technologies to men and women living with and/or affected by HIV

Guidelines re. the use of antiretrovirals as treatment and prevention

Client-centered website committed to advancing reproductive and sexual wellness for individuals, families and communities affected by HIV in San Francisco and beyond

GlobalSHARE Google Group is an easily accessible venue to ask and answer important clinical questions, connect individuals to care, share protocols and tools, circulate important papers and presentations, advertise educational and funding opportunities, and create a space to recognize important work being done in the area of safer conception in the context of HIV 
after attempted conception. A lack of available resources for fertility assessment and management should not preclude safer conception care [94] (Table 3).

Safer conception options are required for those who are not ready for ART, who do not know partner HIV status, or whose partner is not engaged in care, on ART, or adherent. The consensus group agrees that combinations of methods are likely best, but which combinations and how many methods depends on the level of HIV risk, preferences of the individuals, and available services. The importance of balancing a public health approach (which may find PrEP cost-ineffective on top of ART for an infected partner) with personal risk assessment (for example, an individual may not feel confident that his or her partner is adherent to ART) is important to supporting clients while also attending to cost-effectiveness.

Questions regarding implementation are abundant. While ideally a diverse array of providers in HIV-endemic settings should provide these services, the reality is that services will first be offered by a smaller cadre of interested, motivated, or externally-funded providers. How to expand beyond providers with a particular interest in these services remains unclear. Community health workers may play an important role. How to integrate safer conception methods into existing paradigms (e.g. HIV care, sexual and reproductive health care) to leverage resources and maximize efficiencies is unknown. Provider tools that support provision of safer conception counseling and address stigma towards PLWH having children are also needed [82]. We also identified a need for systems to support providers offering care in settings where condomless sex without HIV disclosure among PLWH is criminalized $[77,78]$.

On the client level of implementation, how best to support safer conception programming for HIV-concordant-positive couples, men, same-sex couples, single parents by choice, extended and co-parenting families are outstanding questions. Ensuring that pregnancy planning and reproductive agency and autonomy are promoted within safer conception services and that providers support clients who want to have children but are not yet able to safely disclose to their partner, are outstanding gaps. How to create consumer-friendly services and tools is an area for future research.

\section{Conclusions/Recommendations}

It is time to implement safer conception services. This consensus is supported by science, consumer demand, and global goals to eliminate perinatal HIV transmission. We recommend that providers offer available safer conception services to HIV-affected men and women, and health program administrators integrate safer conception services into existing HIV and reproductive health programs. While the range of service choices may vary across settings, in all settings a minimal set of safer conception services is available. The most fundamental tenets of safer conception counseling are know your HIV-serostatus, know your partner's HIV-serostatus, and wait until the partner living with HIV is on effective ART before attempting pregnancy. These basic tenets should be widely shared with HIV-affected persons, families, communities, and providers. We maintain that this work no longer needs to be the purview of specialists. Answers to outstanding questions will refine care, implementation, and policy but do not need to be resolved prior to offering services.

HIV-related stigma is a key barrier to uptake and delivery of safer conception care. People living with and affected by HIV who consider pregnancy or become pregnant and have children express internalized stigma and describe experiences of stigma from providers and community. Stigma compromises the willingness of clients to seek care and provider willingness to address reproductive goals with clients. It is imperative to acknowledge and support the sexual and reproductive rights of persons living with and affected by HIV and focus efforts on reducing stigma at individual-, provider-, and community-levels, such that HIV-affected men and women can make informed decisions and build healthy families.

We must develop tools that support HIV-affected persons to identify potential risk, engage with safer conception services, and use methods that align with preferences and level of risk. The goal is to engage all populations who could benefit from services including mutually-disclosed HIV-serodiscordant heterosexual couples, men and women living with or exposed to HIV, same sex couples, and seroconcordant-positive couples. Safer conception care must be flexible and address a diversity of clients.

We support development and implementation of strategies that can be adopted in diverse settings to support HIVaffected persons to achieve reproductive goals including increased access to ART and PrEP, HIV-RNA testing, STI testing, sperm washing and assisted reproductive technologies, and fertility care. Programs must be nimble in incorporating discussions about reproductive goals at many points in a client's care without creating undue burden on providers or systems. Integrating safer conception messaging into public health targets for HIV prevention and treatment can maximize synergies.

Provider-initiated conversation is an important gateway to practicing safer conception. Providers across diverse disciplines and training-levels should be able to discuss reproductive options with HIV-affected couples and individuals. Tools to support providers to offer services are 
required, as are strategies and financing to support service integration [95].

Documenting the effect of safer conception is paramount for guidelines and for the confidence of providers and consumers. EMTCT and treatment as prevention initiatives dovetail with safer conception efforts. Data highlighting the advantages of these synergies may catalyze changes in policy and programs. Ensuring that the voices, values, preferences, and experiences of PLWH are at the forefront of safer conception messaging can normalize care-seeking and pregnancy in the context of HIV.

It is time to seize the opportunity to empower people affected by HIV to embrace their fertility goals and utilize safer conception strategies to satisfy goals for pregnancy with minimal HIV transmission risks. This group consensus is strongly supported by science, consumer demand, and global goals to reduce HIV incidence and eliminate perinatal transmission. We invite you to endorse this statement at https://www.hiveonline.org/saferconceptionendorse/.

Acknowledgements We would like to acknowledge gratefully the speakers and panelists at the IAS 2015 satellite session, "Achieving Pregnancy while Minimizing HIV Transmission Risks" (Vancouver) who led the call for this consensus statement including David Bangsberg, Manjulaa Narasimhan, Sheryl van der Poel, Elaine Abrams, Pietro Vernazza, Nelly Mugo, Martha Tholanah, Valerie Nicholson, Lisa Partridge, Mwebesa Bosco Bwana, Mona Loutfy, and Sheila Eshiwani. We also gratefully acknowledge Dazon Dixon, Martha Tholanah, and Marvelous Muchenje for their feedback on an earlier version of this manuscript.

Funding This work was supported in part by NIMH K23MH095655 (LTM) and NICHD R00HD076679 (RH).

Author Contributions Three co-authors (LTM, RH, AK) developed a draft outline of the manuscript which was shared, discussed and modified with co-authors. LTM drafted the statement. All co-authors gave feedback on the draft statement and participated in refining the document. A version of the document was shared with community members and LTM incorporated their feedback to develop a penultimate draft of the manuscript. All co-authors approved the final draft of the consensus statement.

\section{Compliance with Ethical Standards}

Conflict of interest Dr. Cooke is a director of the Low Cost IVF Foundation and a consultant to the WHO. Dr. Okeoma Mmeje is a consultant for the Centers for Disease Control and Prevention (CDC). The content of this manuscript is solely the responsibility and viewpoints of the authors and does not represent the official views or opinions of the $\mathrm{CDC}$, WHO, or $\mathrm{NIH}$. The remaining authors declare no conflicts of interest.

Ethical Approval This article does not contain any studies with human participants or animals performed by any of the authors.

Open Access This article is distributed under the terms of the Creative Commons Attribution 4.0 International License (http://crea tivecommons.org/licenses/by/4.0/), which permits unrestricted use, distribution, and reproduction in any medium, provided you give appropriate credit to the original author(s) and the source, provide a link to the Creative Commons license, and indicate if changes were made.

\section{References}

1. Ogilvie GS, Palepu A, Remple VP, Maan E, Heath K, MacDonald G, et al. Fertility intentions of women of reproductive age living with HIV in British Columbia, Canada. AIDS. 2007;21(Suppl 1):S83-8.

2. Beyeza-Kashesya J, Ekstrom AM, Kaharuza F, Mirembe F, Neema S, Kulane A. My partner wants a child: a cross-sectional study of the determinants of the desire for children among mutually disclosed sero-discordant couples receiving care in Uganda. BMC Public Health. 2010;10:247.

3. Nattabi B, Li J, Thompson SC, Orach CG, Earnest J. A systematic review of factors influencing fertility desires and intentions among people living with HIV/AIDS: implications for policy and service delivery. AIDS Behav. 2009;13(5):949-68.

4. Mantell JE, Exner TM, Cooper D, Bai D, Leu CS, Hoffman S, et al. Pregnancy intent among a sample of recently diagnosed HIV-positive women and men practicing unprotected sex in Cape Town, South Africa. J Acquir Immune Defic Syndr. 2014;67(Suppl 4):S202-9.

5. Fowler MG, Qin M, Fiscus SA, Currier JS, Flynn PM, Chipato $\mathrm{T}$, et al. Benefits and risks of antiretroviral therapy for perinatal HIV prevention. N Engl J Med. 2016;375(18):1726-37.

6. Insight Start Study Group, Lundgren JD, Babiker AG, Gordin F, Emery S, Grund B, et al. Initiation of antiretroviral therapy in early asymptomatic HIV infection. $\mathrm{N}$ Engl $\mathrm{J}$ Med. 2015;373(9):795-807.

7. Rodger AJ, Lodwick R, Schechter M, Deeks S, Amin J, Gilson $\mathrm{R}$, et al. Mortality in well controlled HIV in the continuous antiretroviral therapy arms of the SMART and ESPRIT trials compared with the general population. AIDS. 2013;27(6):973-9.

8. Coates TJ, Kulich M, Celentano DD, Zelaya CE, Chariyalertsak $\mathrm{S}$, Chingono A, et al. Effect of community-based voluntary counselling and testing on HIV incidence and social and behavioural outcomes (NIMH Project Accept; HPTN 043): a clusterrandomised trial. Lancet Glob Health. 2014;2(5):e267-77.

9. Vermund SH, Fidler SJ, Ayles H, Beyers N, Hayes RJ. Can combination prevention strategies reduce HIV transmission in generalized epidemic settings in Africa? The HPTN 071 (PopART) study plan in South Africa and Zambia. J Acquir Immune Defic Syndr. 2013;63(Suppl 2):S221-7.

10. Gruskin S. Pregnancy decisions of women living with HIV: the need for multidisciplinary perspectives. Reprod Health Matters. 2012;20(39 Suppl):1-4.

11. Nyambe M, Kalumire VF, Mohamed Jr S, Mukuan O, Ongech J, Collins L, 000. Maximizing reproductive possibilities and choices for women living with HIV. AIDS. Washington D.C; 2012

12. de Bruyn M, Gatsi-Mallet J, Taylor J, Khudzani Banda M, Sippel S, Simms-Hall T, editors. Advocacy to address the sexual and reproductive rights of women living with HIV at the country level in the south and the north. AIDS. Washington, D.C; 2012

13. Program on Global Health and Human Rights, Insitute for Global Health, University of Southern California, editor. The pregnancy decisions of women living with HIV: Forwarding the Research and Advocacy Agenda. AIDS. Washington, D.C; 2012

14. Debates to guide policies/guideline development on achieving pregnancy for HIV sero-discordant couples. Geneva, Switzerland: World Health Organization, Brocher Foundation; 2014.

15. UNAIDS, Global network of people living with HIV. Positive health, dignity and prevention: a policy framework; 2011. 
16. Kiarie J, Heffron R, Smit J, Gray A, Davies N, Beyeza-Kashesya $\mathrm{J}$ ea, editors. Supporting HIV-affected women and men to safely meet reproductive goals: insights into contraception, safer conception, and infertility.\#WESY0601-08.. AIDS2016. Durban; 2016

17. Mmeje O, Eshiwani S, Ngoroge B, Davies N. HIV and infertility: a pragmatic approach for evaluation and management in low-resource settings. Abstracts FRWA0301-06. AIDS2016; Durban; 2016.

18. Osegura-Bhatnagar Y, Kaida A, Wambui J, Machete R, Kumalo $\mathrm{G}$, Weber-Kilpack T, et al. At the intersection of reproductive empowerment and ending HIV transmission: Expanding safer conception options. Session\#CUGS08. AIDS2016; Durban; 2016.

19. Kaida A, Bangsberg DR, Gray G, Hogg RS, King R, Miller CL. Editorial: introduction to the Supplement on HIV, HAART, and fertility in sub-Saharan Africa. AIDS Behav. 2009;13(Suppl $1): 1-4$.

20. Wilcher R, Cates W Jr, Gregson S. Family planning and HIV: strange bedfellows no longer. AIDS. 2009;23(Suppl 1):S1-6.

21. Wilcher R, Cates W Jr, Baeten JM. Family planning and HIV: two steps forward. AIDS. 2013;27(Suppl 1):S1-4.

22. Loutfy M, Khosla R, Narasimhan M. Advancing the sexual and reproductive health and human rights of women living with HIV. J Int AIDS Soc. 2015;18(Suppl 5):20760.

23. HIV: a hub of positive reproductive and sexual health. 2016. http://www.HIVEonline.org.

24. Centres for Reproductive Assistance Techniques in HIV in Europe (CREAThE). http://www.creathe.org.

25. Ethics Committee of the American Society for Reproductive Medicine. Human immunodeficiency virus (HIV) and infertility treatment: a committee opinion. Fertil Steril. 2015. doi:10.1016/ j.fertnstert.2015.04.004.

26. Trust Salamander. Building a safe house on firm ground: key findings from a global values and preferences survey regarding the sexual and reproductive health and human rights of women living with HIV. Geneva: World Health Organization; 2014.

27. Loutfy MR, Margolese S, Money DM, Gysler M, Hamilton S, Yudin $\mathrm{MH}$, et al. Canadian HIV pregnancy planning guidelines. J Obstet Gynaecol Can. 2012;34(6):575-90.

28. Canadian HIV Pregnancy Planning Guideline Development Team, Society of Obstetricians Gynecologists of Canada, Canadian Fertility Andrology Society, et al. Canadian HIV Pregnancy Planning Guidelines: No. 278, June 2012. Int J Gynaecol Obstet. 2012;119(1):89-99.

29. Department of Health Republic of South Africa. National contraception and fertility planning policy and service delivery guidelines. Pretoria; 2012.

30. Fakoya A, Lamba H, Mackie N, Nandwani R, Brown A, Bernard E, et al. British HIV Association, BASHH and FSRH guidelines for the management of the sexual and reproductive health of people living with HIV infection 2008. HIV Med. 2008;9(9):681-720.

31. Kaida A, Matthews LT, Heffron R, van der Poel S, Bangsberg DR, Narasimhan M. Achieving pregnancy while minimizing HIV transmission risks: Safer conception research, policy and programming priorities for HIV-affected individuals and couples. Satellite session report. 8th International Conference on HIV Pathogenesis, Treatment, and Prevention. Vancouver, BC, Canada. July 2015; 2015.

32. Rahangdale L, Stewart A, Stewart RD, Badell M, Levison J, Ellis $\mathrm{P}$, et al. Pregnancy intentions among women living with HIV in the United States. J Acquir Immune Defic Syndr. 2014;65(3):306-11.

33. Finocchario-Kessler S, Dariotis JK, Sweat MD, Trent ME, Keller JM, Hafeez Q, et al. Do HIV-infected women want to discuss reproductive plans with providers, and are those conversations occurring? AIDS Patient Care STDS. 2010;24(5):317-23.

34. Matthews LT, Moore L, Milford C, Greener R, Mosery FN, Rifkin R, et al. "If I don't use a condom... I would be stressed in my heart that I've done something wrong": routine prevention messages preclude safer conception counseling for HIV-infected men and women in South Africa. AIDS Behav. 2015.

35. Steiner RJ, Black V, Rees H, Schwartz SR. low receipt and uptake of safer conception messages in routine hiv care: findings from a prospective cohort of women living with HIV in South Africa. J Acquir Immune Defic Syndr. 2016;72(1):105-13.

36. Mindry D, Wagner G, Lake J, Smith A, Linnemayr S, Quinn M, et al. Fertility desires among HIV-infected men and women in Los Angeles County: client needs and provider perspectives. Matern Child Health J. 2013;17(4):593-600.

37. Matthews LT, Milford C, Kaida A, Ehrlich MJ, Ng C, Greener $\mathrm{R}$, et al. Lost opportunities to reduce periconception HIV transmission: safer conception counseling by South African providers addresses perinatal but not sexual HIV transmission. J Acquir Immune Defic Syndr. 2014;67(Suppl 4):210-7.

38. Gogna ML, Pecheny MM, Ibarlucia I, Manzelli H, Lopez SB. The reproductive needs and rights of people living with HIV in Argentina: health service users' and providers' perspectives. Soc Sci Med. 2009;69(6):813-20.

39. Loutfy MR, Sherr L, Sonnenberg-Schwan U, Walmsley SL, Johnson M, d'Arminio Monforte A, et al. Caring for women living with HIV: gaps in the evidence. J Int AIDS Soc. 2013; 16:18509.

40. Crankshaw TL, Mindry D, Munthree C, Letsoalo T, Maharaj P. Challenges with couples, serodiscordance and HIV disclosure: healthcare provider perspectives on delivering safer conception services for HIV-affected couples, South Africa. J Int AIDS Soc. 2014; 17:18832.

41. Matthews LT, Bajunirwe F, Kastner J, Sanyu N, Akatukwasa C, $\mathrm{Ng} \mathrm{C}$, et al. "I always worry about what might happen ahead": implementing Safer conception services in the current environment of reproductive counseling for HIV-affected men and women in Uganda. Biomed Res Int. 2016;2016:4195762.

42. Seidman DL, Weber S, Timoney MT, Oza KK, Mullins E, Cohan DL, et al. Use of HIV pre-exposure prophylaxis during the preconception, antepartum and postpartum periods at two United States medical centers. Am J Obstet Gynecol. 2016. doi:10.1016/j.ajog.2016.06.020.

43. Matthews LT, Crankshaw T, Giddy J, Kaida A, Smit JA, Ware NC, et al. Reproductive decision-making and periconception practices among HIV-positive men and women attending HIV services in Durban, South Africa. AIDS Behav. 2013;17(2):461-70.

44. Technau KG, Kalk E, Coovadia A, Black V, Pickerill S, Mellins $\mathrm{CA}$, et al. Timing of maternal HIV testing and uptake of prevention of mother-to-child transmission interventions among women and their infected infants in Johannesburg, South Africa. J Acquir Immune Defic Syndr. 2014;65(5):e170-8.

45. Matthews LT, Moore L, Crankshaw TL, Milford C, Mosery FN, Greener R, et al. South Africans with recent pregnancy rarely know partner's HIV serostatus: implications for serodiscordant couples interventions. BMC Public Health. 2014;14:843.

46. Kaida A, Kastner J, Ng C, Sanyu N, Kusasira A, Kabakyenga J, et al. Barriers and promoters to uptake of safer conception strategies among HIV-serodiscordant couples with fertility intention in Mbarara, Uganda. AIDS Res Human Retrovir. 2014;30(Supplement 1):A61-2.

47. Schwartz SR, West N, Phofa R, Yende N, Sanne I, Bassett J, et al. Acceptability and preferences for safer conception HIV prevention strategies: a qualitative study. Int J STD AIDS. 2015;27:984-92. 
48. Ngure K, Heffron R, Curran K, Vusha S, Ngutu M, Mugo N, et al. I knew i would be safer. experiences of Kenyan HIV serodiscordant couples soon after pre-exposure prophylaxis (prep) initiation. AIDS Patient Care STDS. 2016;30(2):78-83.

49. Khidir H, Psaros C, Greener L, O’Neil KF, Mathenjwa M, Mosery FN, et al. Developing a safer conception intervention for men living with HIV in South Africa. AIDS Behav. 2017. doi:10.1007/s10461-017-1719-4.

50. World Health Organization. Guideline on when to start antiretroviral therapy and on pre-exposure prophylaxis for HIV. Geneva: WHO; 2015.

51. Mujugira A, Celum C, Coombs RW, Campbell JD, Ndase P, Ronald A, et al. HIV transmission risk persists during the first 6 months of antiretroviral therapy. J Acquir Immune Defic Syndr. 2016;72:579.

52. Cohen MS, Chen YQ, McCauley M, Gamble T, Hosseinipour MC, Kumarasamy N, et al. Prevention of HIV-1 infection with early antiretroviral therapy. N Engl J Med. 2011;365:493-505.

53. Centers for Disease Control and Prevention, U.S. Department of Health and Human Services. Updated guidelines for antiretroviral postexposure prophylaxis after sexual, injection drug use, or other nonoccupational exposure to HIV-United States, 2016.

54. Were EO, Heffron R, Mugo NR, Celum C, Mujugira A, Bukusi EA, et al. Pre-exposure prophylaxis does not affect the fertility of HIV-1-uninfected men. AIDS. 2014;28(13):1977-82.

55. Mofenson LM, Baggaley RC, Mameletzis I. Tenofovir disoproxil fumarate safety for women and their infants during pregnancy and breastfeeding. AIDS. 2017;31(2):213-32.

56. Nachega JB, Uthman OA, Mofenson LM, Anderson JR, Kanters S, Renaud F, et al. Safety of tenofovir disoproxil fumarate-based antiretroviral therapy regimens in pregnancy for HIV-infected women and their infants: a systematic review and meta-analysis. J Acquir Immune Defic Syndr. 2017. doi:10.1097/QAI. 0000000000001359.

57. Mofenson LM. Tenofovir pre-exposure prophylaxis for pregnant and breastfeeding women at risk of HIV infection: the time is now. PLoS Med. 2016;13(9):e1002133.

58. Mmeje O, Cohen C, Cohan D. Evaluating safer conception options for HIV-infected female/HIV-uninfected male serodiscordant couples: a closer look at vaginal insemination. Infect Dis Obstet Gynecol. 2012. doi:10.1155/2012/587651.

59. Mills E, Cooper C, Anema A, Guyatt G. Male circumcision for the prevention of heterosexually acquired HIV infection: a metaanalysis of randomized trials involving 11,050 men. HIV Med. 2008;9(6):332-5.

60. Grosskurth H, Mosha F, Todd J, Mwijarubi E, Klokke A, Senkoro K, et al. Impact of improved treatment of sexually transmitted diseases on HIV infection in rural Tanzania: randomised controlled trial. Lancet. 1995;346(8974):530-6.

61. Wawer MJ, Gray RH, Sewankambo NK, Serwadda D, Paxton L, Berkley S, et al. A randomized, community trial of intensive sexually transmitted disease control for AIDS prevention, Rakai, Uganda. AIDS. 1998;12(10):1211-25.

62. Liao C, Wahab M, Anderson J, Coleman JS. Reclaiming fertility awareness methods to inform timed intercourse for HIV serodiscordant couples attempting to conceive. J Int AIDS Soc. 2015;18:19447.

63. Semprini AE, Levi-Setti P, Bozzo M, Ravizza M, Taglioretti A, Sulpizio $\mathrm{P}$, et al. Insemination of HIV-negative women with processed semen of HIV-positive partners. Lancet. 1992;340(8831):1317-9.

64. Zafer M, Horvath H, Mmeje O, van der Poel S, Semprini AE, Rutherford G, et al. Effectiveness of semen washing to prevent human immunodeficiency virus (HIV) transmission and assist pregnancy in HIV-discordant couples: a systematic review and meta-analysis. Fertil Steril. 2016;105(3):645-55.
65. Zakarin Safier L, Sauer MV. Fertility care interventions should be provided as the first line options for HIV + serodiscordant couples who desire children in settings with affordable access to care, regardless of their fertility status. J Int AIDS Soc. 2017;20(Suppl 1):12-7.

66. Beyeza-Kashesya J. Prevalence, consequences and key issues in the management of infertility and subfertility among men and women living with HIV.\#WESY0605. AIDS2016; Durban, South Africa; 2016.

67. Bunting L, Boivin J. Development and preliminary validation of the fertility status awareness tool: FertisTaT. Hum Reprod. 2010;25(7):1722-33.

68. Finocchario-Kessler S, Mabachi N, Dariotis JK, Anderson J, Goggin K, Sweat M. "We weren't using condoms because we were trying to conceive": the need for reproductive counseling for HIV-positive women in clinical care. AIDS Patient Care STDS. 2012;26(11):700-7.

69. Panozzo L, Battegay M, Friedl A, Vernazza PL. High risk behaviour and fertility desires among heterosexual HIV-positive patients with a serodiscordant partner-two challenging issues. Swiss Med Wkly. 2003;133(7-8):124-7.

70. Vernazza PL, Graf I, Sonnenberg-Schwan U, Geit M, Meurer A. Preexposure prophylaxis and timed intercourse for HIV-discordant couples willing to conceive a child. AIDS. 2011;25(16):2005-8.

71. Schwartz SR, Bassett J, Sanne I, Phofa R, Yende N, Van Rie A. Implementation of a safer conception service for HIV-affected couples in South Africa. AIDS. 2014;28(Suppl 3):S277-85.

72. Heffron R, Mugo N, Ngure K, Bukusi E, Odoyo J, Katabira E, et al., editors. PrEP and ART reduce HIV transmission between members of HIV serodiscordant couples during pregnancy and pregnancy attempts. Abstract THPDC0102. AIDS 2016; Durban; 2016.

73. Whetham J, Taylor S, Charlwood L, Keith T, Howell R, McInnes $\mathrm{C}$, et al. Pre-exposure prophylaxis for conception (PrEP-C) as a risk reduction strategy in HIV-positive men and HIV-negative women in the UK. AIDS Care. 2013. doi:10.1080/ 09540121.2013.819406.

74. UNFPA. Programme of action of the international conference on population and development, Cairo, 1994. New York: United Nations; 1995.

75. Delvaux T, Nostlinger C. Reproductive choice for women and men living with HIV: contraception, abortion and fertility. Reprod Health Matters. 2007;15(29 Suppl):46-66.

76. Obermeyer CM, Baijal P, Pegurri E. Facilitating HIV disclosure across diverse settings: a review. Am J Public Health. 2011;101(6):1011-23.

77. UNAIDS. Criminalisation of HIV non-disclosure, exposure, and transmission: Background and current landscape. Geneva: UNAIDS; 2012.

78. Patterson SE, Milloy MJ, Ogilvie G, Greene S, Nicholson V, Vonn M, et al. The impact of criminalization of HIV non-disclosure on the healthcare engagement of women living with HIV in Canada: a comprehensive review of the evidence. J Int AIDS Soc. 2015;18:20572.

79. Matthews LT, Crankshaw T, Giddy J, Kaida A, Psaros C, Ware NC, et al. Reproductive counseling by clinic healthcare workers in Durban, South Africa: perspectives from HIV-infected men and women reporting serodiscordant partners. Infect Dis Obstet Gynecol. 2012. doi:10.1155/2012/146348.

80. Schwartz SR, Mehta SH, Taha TE, Rees HV, Venter F, Black V. High pregnancy intentions and missed opportunities for patientprovider communication about fertility in a South African cohort of HIV-positive women on antiretroviral therapy. AIDS Behav. 2012;16(1):69-78.

81. Finocchario-Kessler S, Wanyenze R, Mindry D, Beyeza-Kashesya J, Goggin K, Nabiryo C, et al. "I may not say we really have a 
method, it is gambling work": knowledge and acceptability of safer conception methods among providers and HIV clients in Uganda. Health Care Women Int. 2014;35(7-9):896-917.

82. Mmeje O, Njoroge B, Akama E, Leddy A, Breitnauer B, Darbes $\mathrm{L}$, et al. Perspectives of healthcare providers and HIV-affected individuals and couples during the development of a Safer Conception Counseling Toolkit in Kenya: stigma, fears, and recommendations for the delivery of services. AIDS Care. 2016;28(6):750-7.

83. Stekelenburg J, Jager BE, Kolk PR, Westen EH, van der Kwaak A, Wolffers IN. Health care seeking behaviour and utilisation of traditional healers in Kalabo, Zambia. Health Policy. 2005;71(1):67-81.

84. Dyer SJ, Abrahams N, Hoffman M, van der Spuy ZM. Infertility in South Africa: women's reproductive health knowledge and treatment-seeking behaviour for involuntary childlessness. Hum Reprod. 2002;17(6):1657-62.

85. Haberer JE. Current concepts for PrEP adherence in the PrEP revolution: from clinical trials to routine practice. Curr Opin HIV AIDS. 2016;11(1):10-7.

86. Mugwanya KK, Hendrix CW, Mugo NR, Marzinke M, Katabira ET, Ngure K, et al. Pre-exposure prophylaxis use by breastfeeding HIV-uninfected women: a prospective short-term study of antiretroviral excretion in breast milk and infant absorption. PLoS Med. 2016;13(9):e1002132.

87. Bekker LG, Rebe K, Venter F, Maartens G, Moorhouse M, Conradie F, et al. Southern African guidelines on the safe use of pre-exposure prophylaxis in persons at risk of acquiring HIV-1 infection. South Afr J HIV Med. 2016;17:1-11.

88. Microbicide Trials Network with AVAC, IMPAACT, IPM, Jhpiego, PEPFAR, editors. HIV prevention for pregnant and breastfeeding women: long overdue. But is it time to deliver? MOSA35. AIDS2016; Durban; 2016.

89. ClinicalTrials.gov. PrEPception: Expanding Assisted Reproductive Options for Serodiscordant Couples 2014. http://clin icaltrials.gov/show/NCT02233192.

90. Myers JE, Sepkowitz KA. A pill for HIV prevention: deja vu all over again? Clin Infect Dis. 2013;56(11):1604-12.
91. Black V, Davies N, Williams BG, Rees HV, Schwartz SR. Establishing conception intentions and safer conception services for eliminating the vertical, and reducing the horizontal, transmission of HIV. BJOG. 2016;123(10):1585-8.

92. HIV and infertility: a pragmatic approach for evaluation and management in low-resource environments. FRWSO3. AIDS2016; Durban; 2016.

93. American College of Obstetrics, Gynecologists Committee on Gynecologic Practice, Practice Committee of the American Society for Reproductive Medicine. Female age-related fertility decline. Committee Opinion No. 589. Obstet Gynecol. 2014;123(3):719-21.

94. Dyer SJ, Sherwood K, McIntyre D, Ataguba JE. Catastrophic payment for assisted reproduction techniques with conventional ovarian stimulation in the public health sector of South Africa: frequency and coping strategies. Hum Reprod. 2013;28(10):2755-64.

95. World Health Organization Department of HIV AIDS. Sexual and reproductive health of women living with HIV/AIDS. Geneva: WHO; 2006.

96. Weller S, Davis K. Condom effectiveness in reducing heterosexual HIV transmission. Cochrane Database of Syst Rev. 2002. doi:10.1002/14651858.CD003255.

97. Rodger AJ, Cambiano V, Bruun T, Vernazza P, Collins S, van Lunzen J, et al. Sexual activity without condoms and risk of HIV transmission in serodifferent couples when the HIV-positive partner is using suppressive antiretroviral therapy. JAMA. 2016;316(2):171-81.

98. Thigpen MC, Kebaabetswe PM, Paxton LA, Smith DK, Rose CE, Segolodi TM, et al. Antiretroviral preexposure prophylaxis for heterosexual HIV transmission in Botswana. N Engl J Med. 2012;367(5):423-34.

99. Baeten JM, Donnell D, Ndase P, Mugo NR, Campbell JD, Wangisi J, et al. Antiretroviral prophylaxis for HIV prevention in heterosexual men and women. $\mathrm{N}$ Engl $\mathrm{J}$ Med. 2012;367(5):399-410.

100. Phillips B, Ball C, Sackett D, Badenoch D, Straus S, Haynes B, et al. Oxford Centre for Evidence-based Medicin-levels of evidence: Oxford University; 2009. http://www.cebm.net/index. aspx?o=1025. Accessed Mar 2009 